\title{
FESTINA LENTE
}

AUGUSTA EMPRESA CORRER A ESPACIO

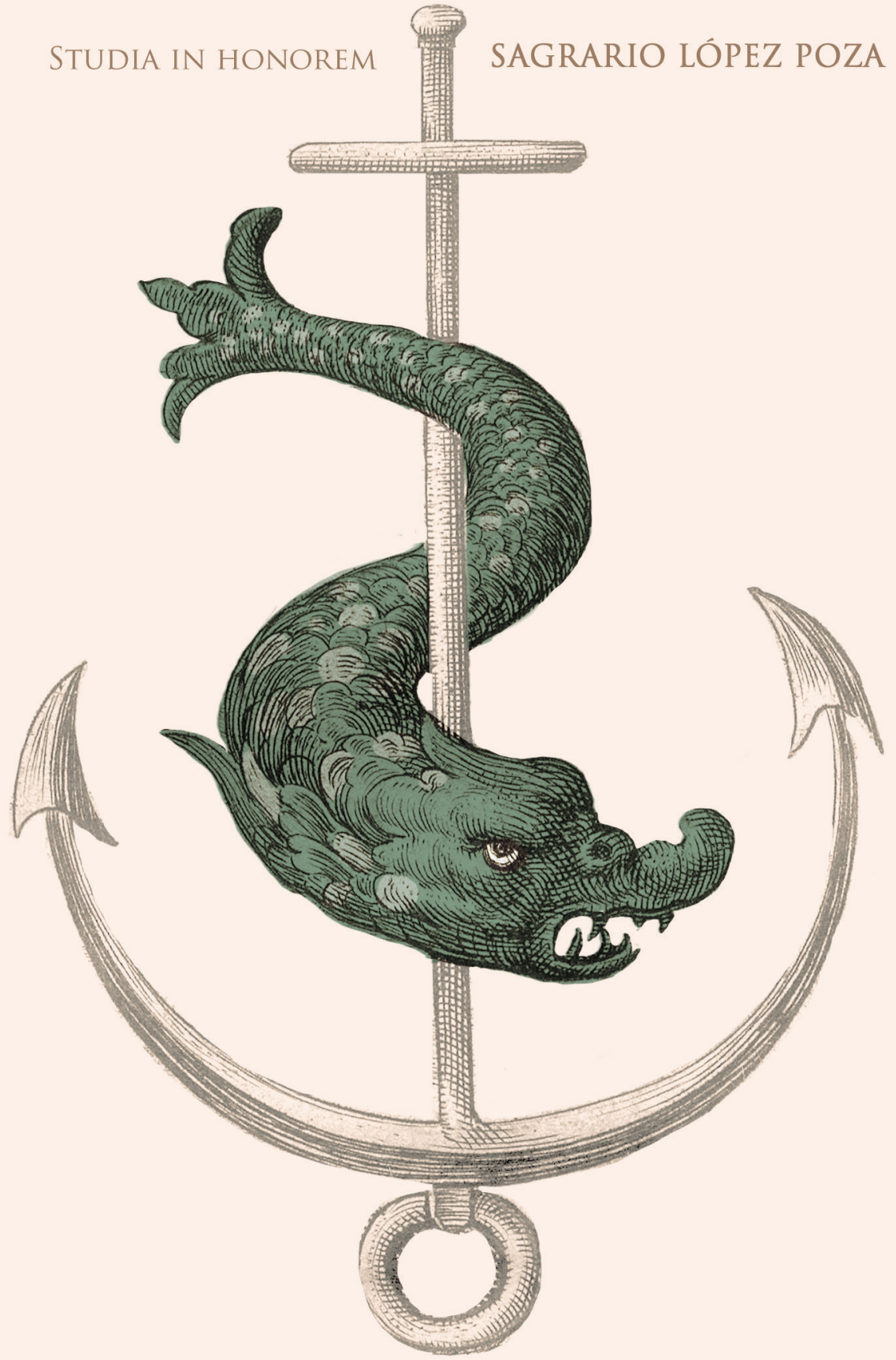

EDICIÓN AL CUIDADO DE: 
Festina Lente. Augusta empresa correr a espacio. Studia in honorem Sagrario López Poza

Carlota Fernández Travieso

Nieves Pena Sueiro

(editoras)

A Coruña 2019

Universidade da Coruña

Servizo de Publicacións

Coa colaboración de: BIDISO, Grupo Hispania 
Profesora Sagrario López Poza

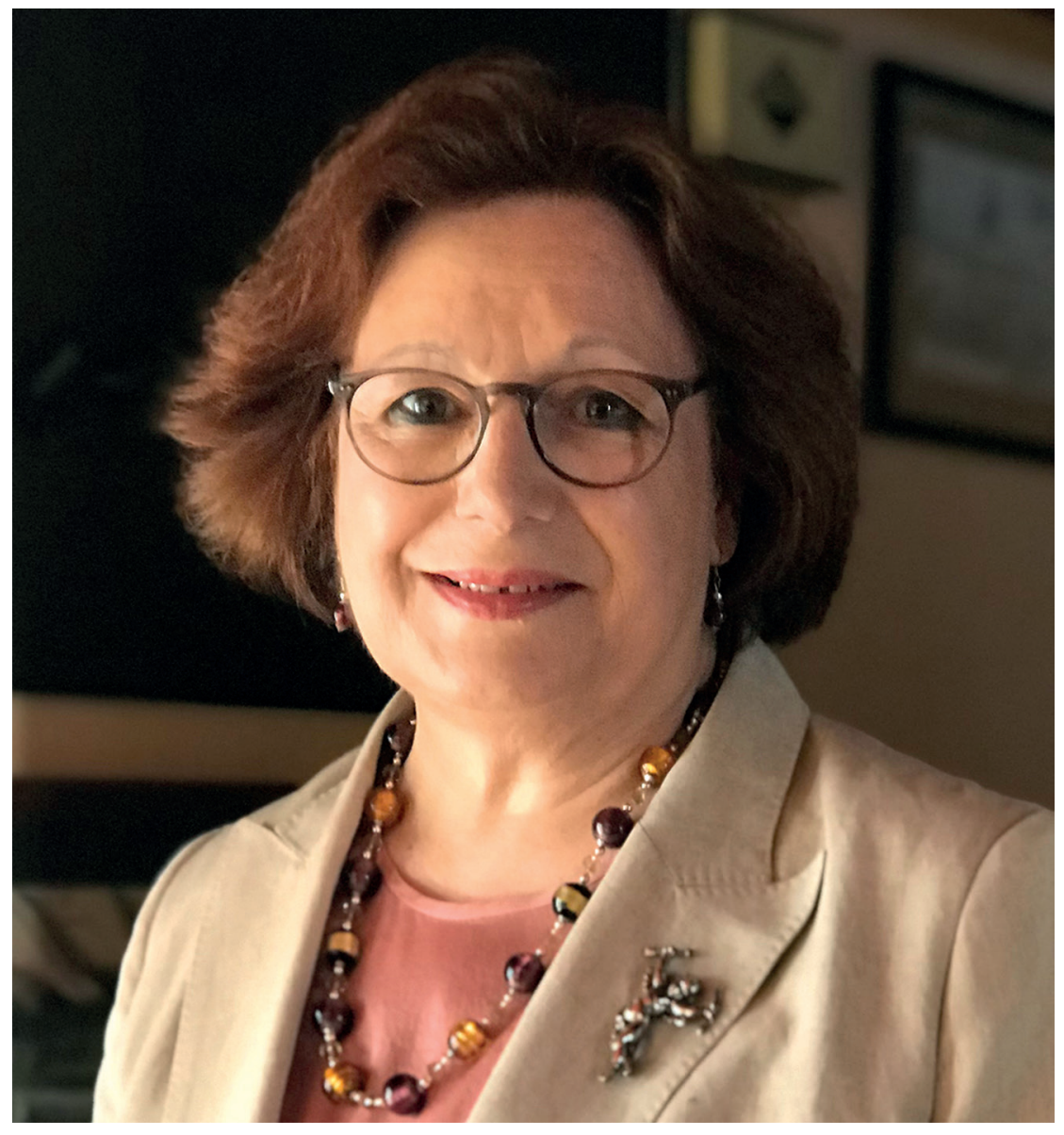


Festina Lente. Augusta empresa correr a espacio. Studia in honorem Sagrario López Poza

Carlota Fernández Travieso; Nieves Pena Sueiro (editoras)

A Coruña, 2019

Universidade da Coruña, Servizo de Publicacións / Proyecto BIDISO, Grupo

Hispania (UDC)

Colección: Homenaxes n. ${ }^{\circ} 15$

N. ${ }^{\circ}$ de páginas: 300

$17 \times 24 \mathrm{~cm}$

Índice: p. 7-8

ISBN: 9788497497367

ISBN: 9788497497374 (electrónico)

Depósito Legal: C1872-2019

DOI: https://doi.org/10.17979/9788497497374

CDU: 821.134.2(082.2)^LOPEZ-POZA

IBIC: DS | 2ADS | DQ

Edita:

Universidade da Coruña, Servizo de Publicacións <www.udc.gal/publicacions>

Coa colaboración de: Proyecto Biblioteca Digital Siglo de Oro 5 (FFI2015 65779-P), MICIN-FEDER. Grupo Hispania, Universidade da Coruña

(C) de la edición: Universidade da Coruña

(C) de los textos: los autores

Diseño de cubierta: Paula Lupiáñez (Cirugía Gráfica. Madrid)

Diseño de interior: Juan de la Fuente

Impreso en Lugami Artes Gráficas, Betanzos (A Coruña, España)

Distribución: <www.udc.es/gl/publicacions/distribucion>

Reservados todos los derechos. Ni la totalidad ni parte de este libro puede reproducirse o transmitirse por ningún procedimiento electrónico o mecánico, incluyendo fotocopia, grabación magnética o cualquier almacenamiento de información y sistema de recuperación, sin el permiso previo y por escrito de las personas titulares del copyright. 


\section{ÍNDICE}

Presentación

\section{Sagrario López Poza. Semblanzas}

Begoña López Bueno

Sagrario López Poza: la pasión del saber y la generosidad del compartir

Henry EtTinghausen

Sagrario López Poza: quevedista, relacionera, relacionista

Aurora EgIDO

Qui seminat, metet. Los trabajos sobre Emblemática y erudición humanística de Sagrario López Poza

Nieves R. Brisaboa, Ángeles Saavedra Places y Nieves Pena Sueiro

Sagrario López Poza, humanista digital

Bibliografía de Sagrario López Poza

\section{Estudios en homenaje a la profesora Sagrario López Poza}

Carmen Espejo Cala y Francisco de Paula Baena Sánchez

Producción, estructura y mercado de la información en las relaciones de sucesos sevillanas (1500-1650)

Carlota Fernández Travieso

Maquiavelo y la religión de los romanos en el Libro primero de 1571 y el Libro segundo del Espejo del perfecto príncipe cristiano de Francisco de Monzón

José Julio García Arranz

De sirena a serena. Relaciones entre emblemática y heráldica en un documento manuscrito de finales del siglo XVII 
Cirilo García Román - Alejandro Martínez Sobrino

De nuevo sobre los «Cincuenta y nueve emblemas» de Baltasar de Vitoria:

I. CEDIT VICTORIA VICTIS

\section{Consuelo Gonzalo García}

«En breve ha de haber noticia en hartas partes dello». La historia textual y editorial de la relación del fuego en la isla del Pico en 1562

\section{VALENTINA NiDER}

Confusión de confusiones de José Penso de la Vega (1688) y la Tabla de Cebes a través de Agostino Mascardi (con una mirada en los Pensieri de Alessandro Tassoni)

\section{TONInA PABA}

Relación de la fiesta que se hizo al feliz parto de la Excell. Señora Doña María Antíoga de Alagón y Pimentel, Princesa de Pomblín y de Venosa, di Jerónimo Mathías De Litala y Sanna (Cagliari, 1670): edizione e studio

Nieves Pena Sueiro

Los casamientos de Felipe de Austria y María Manuela de Portugal en las relaciones de sucesos

Javier Ruiz Astiz

En Pamplona también se imprimen relaciones de sucesos: el taller de Martín Labayen (1636-1648) 


\title{
En Pamplona se imprimen relaciones de sucesos: el taller de Martín de Labayen (1636-1648)
}

\author{
Javier Ruiz Astiz ${ }^{1}$ \\ Universidade da Coruña
}

1 Este trabajo se ha realizado en el marco del proyecto Biblioteca Digital Siglo de Oro 5 (BIDISO 5), con referencia: FFI2015-65779-P, financiado por el Ministerio de Economía y Competitividad del Gobierno de España y el Fondo Europeo de Desarrollo Regional (FEDER) desde el 1-01-2016 hasta el 31-12-2019, que se integra en el grupo de investigación HISPANIA (G000208) de la Universidade da Coruña. 


\section{Resumen}

En Pamplona circularon, al igual que en el resto de la Monarquía Hispánica, las relaciones de sucesos, por lo que el reino de Navarra no estuvo al margen de este negocio editorial. Muestra evidente de este fenómeno serán los testimonios salidos del taller de Martín de Labayen, quien de manera puntual publicó diferentes relaciones entre 1636 y 1648 . Pero este trabajo no solo aborda su producción o su figura como editor, sino que, además, nos sumergiremos en otros aspectos de su vida como impresor gracias a los documentos de archivo rescatados.

\section{Palabras clave}

Relaciones de sucesos, Martín de Labayen, Pamplona, Historia del Libro, Siglo XVII.

\section{Abstract}

In Pamplona circulated, as in the rest of the Hispanic Monarchy, the news pamphlets, so the Kingdom of Navarre was not excluded from this publishing business. Obvious evidence of this phenomenon will be the testimonies from the workshop of Martín de Labayen, who promptly published different news pamphlets between 1636 and 1648. But this work not only addresses its production or its figure as editor, but also we will immerse ourselves in other aspects of his life as a printer thanks to the archived documents rescued.

\section{Keywords}

News Pamphlets, Martín de Labayen, Pamplona, Book History, XVIIth century. 


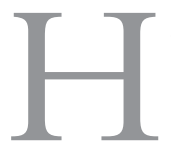
ace tiempo que las relaciones de sucesos no constituyen un recurso documental, bibliográfico e informativo extraño, puesto que en las últimas dos décadas han proliferado toda una serie de estudios que las vienen demandado desde múltiples perspectivas: histórica, filológica o bibliográfica, entre otras. Aquí sobresale la figura de Sagrario López Poza, quien durante tantos años se ha dedicado a estudiar este tipo de impresos tan curiosos para desbrozar la infinidad de interrogantes que se ciernen sobre ellos y destacar su valor bibliográfico y documental; lo realmente importante es, como ella misma señaló, «localizar, preservar del deterioro del tiempo y difundir estas piezas bibliográficas para el mejor conocimiento de nuestro patrimonio histórico y literario» (López Poza, 2006: 134).

No hay duda de que los trabajos de la profesora López Poza, junto a los de toda una serie de académicos españoles, italianos o franceses, nos permiten conocer aspectos que hasta la fecha nos eran desconocidos o los conocíamos sin llegar a profundizar mucho en ellos. Así sucede, por ejemplo, con el avance experimentado en todo lo relacionado con el proceso de creación y distribución de estos impresos, lo que, a su vez, nos acerca a su transmisión textual, su intrahistoria editorial y las redes informativas que se tejieron en Europa durante los siglos modernos.

Este rico corpus de trabajos académicos tan heterogéneos es posible por la ingente cantidad de relaciones que se conservan en numerosas bibliotecas, ya que, como apuntó Víctor Infantes, «existir, existen (y a miles); otra cosa es saber qué son» (Infantes, 1996: 203). De este modo, a pesar de que se ha escrito bastante al respecto, no resulta nada sencillo discernir qué es una relación de sucesos, por lo que huelga retomar un análisis riguroso de este tipo de impresos. Se trata, en definitiva, de un cometido que aún tenemos pendiente de abordar de forma certera todos los que estamos interesados en estos textos noticiosos desde que Pena Sueiro (2001: 43-44) publicó en 2001 su Estado de la cuestión sobre el estudio de las relaciones de sucesos. De ahí que resulte necesario introducir en el debate bibliográfico la actualización del concepto de relación (Ruiz Astiz y Pena Sueiro, 2019).

Al margen de esto, sean consideradas o no como un producto y/o género editorial, lo cierto es que las relaciones de sucesos florecieron 
por toda la geografía hispana en pleno Siglo de Oro. No obstante, nadie duda de que Madrid, Barcelona o Sevilla ostentaron una posición privilegiada en la producción y comercialización de este tipo de productos. A pesar de esto, otras ciudades peninsulares se unieron al circuito de noticias que se fue tejiendo entre los siglos XVI y XVII. Un circuito en el que nos encontramos algunos testimonios surgidos de las prensas pamplonesas, si bien hasta la fecha se tendía a pensar que Pamplona era una urbe ajena a tales impresos, puesto que, aun con las referencias que Arigita (1901) y Pérez Goyena (1947) recogían en sus respectivos repertorios, no existía ningún trabajo que aglutinase las relaciones de sucesos editadas en Navarra.

No obstante, para paliar esta situación he publicado recientemente un estudio que reúne en un repertorio bibliográfico las 35 relaciones de sucesos que fueron publicadas en Pamplona durante el siglo XVII (Ruiz Astiz, 2019: 1-47). Esta investigación —donde se han podido identificar 9 relaciones que no fueron consultadas por ninguno de los bibliógrafos reseñados - se une al artículo que publiqué en 2015 sobre un impreso que Martín de Labayen publicó fruto del enfrentamiento entre Francia y España en 1647 (Ruiz Astiz, 2015: 619-634). Ambos trabajos vienen a demostrar que la industria editorial de Navarra no fue reacia a la edición de noticias sobre batallas, paces, entradas reales, actos festivos, exequias fúnebres o sucesos extraordinarios. Nada más lejos de la realidad, ya que, aunque el volumen de impresos sea mucho más modesto que en otras zonas de la geografia hispana, sí surgieron puntualmente de los talleres de imprenta ubicados en Pamplona algunas relaciones de sucesos.

Esto nos lleva a pensar que la imprenta navarra del XVII, pese a seguir siendo un negocio dependiente de los encargos institucionales y estar fuertemente subvencionado por las autoridades locales, experimentó un cierto esplendor en clara contraposición con la situación de penuria vivida en buena parte de la centuria precedente. Podemos afirmar, de este modo, que entre 1600 y 1650 los talleres de imprenta radicados en el reino dieron signos de una mayor apertura editorial, pues ya no era principalmente una industria de carácter institucional, sino que se fue convirtiendo en una industria más comercial, lo que se constata en los géneros literarios y las temáticas surgidas de sus prensas. Entre todas esas novedades, como no podía ser de otra forma, tuvieron cabida las relaciones de sucesos. 
Aun con todo, la capital navarra no puede compararse con los grandes centros editoriales de la Península Ibérica, puesto que mientras en las cinco primeras décadas del siglo XVII se editaron en Barcelona cerca de 500 relaciones, en Sevilla más de 250 o en Valencia casi 100 (Pena Sueiro y Fernández Travieso, 2013: 128), de las prensas pamplonesas identificamos un total de 25 (Ruiz Astiz, 2019: 5-6). Como es evidente, la pujanza comercial de Pamplona no fue la misma que la de las urbes mencionadas, un hecho que pudo deberse a una concatenación de circunstancias:

a) El escaso número de impresores y talleres asentados en Pamplona, lo que influyó directamente en sus capacidades productivas.

b) La dependencia de las imprentas locales de los encargos oficiales o de los que se costeaban sus propios autores.

c) Cierto interés por editar textos de temática local o relacionados con Navarra porque eran más atractivos para los lectores del reino.

d) Un entramado legal que, desde la Pragmática de 1558, prohibía la entrada en los reinos de Castilla de toda obra impresa fuera de los mismos, a no ser que tuviese licencia del Consejo de Castilla. Dicha situación motivó las quejas de impresores y libreros porque los impresos navarros no podían venderse libremente.

e) Pamplona — dado su carácter administrativo y militar, su escasa pujanza en la industria editorial y sus reducidas dimensiones poblacionales- no quedó al margen del circuito de noticias, pero no constituyó un foco de primera magnitud, por lo que se vio relegada a un papel secundario.

Todos estos aspectos unidos entre sí, provocaron que los tipógrafos pamploneses se mostrasen reacios a emprender aventuras editoriales por lo costoso de las mismas, aunque advertimos algunos impresores que sí trataron de editar textos noticiosos sobre asuntos que trascendían los temas locales. Dicho esto, no podemos aseverar que las relaciones de sucesos no fuesen de interés para los impresores locales, sino más bien que se trató de cometidos puntuales ante hechos o acontecimientos de cierta relevancia, sobre todo locales, aunque no desmerecieron otros asuntos ajenos al reino o indirectamente relacionados con sus intereses. 
Son varios los tipógrafos que podríamos destacar en tierras navarras, pero, sin duda, junto a Carlos de Labayen (1578-1632), sobresale la figura de su hermano Martín, pues de su taller —al menos que tengamos noticia- salieron ricas y variadas relaciones de sucesos entre 1636 y 1648. Su producción, las características y temáticas de dichos impresos, así como su iniciativa editorial en aquel contexto tan convulso es lo que trataremos de desgranar en las próximas páginas, durante las cuales nos vamos a sumergir en su taller gracias a los testimonios documentales localizados en archivos y bibliotecas.

\section{El trabajo BibliogrÁfico: METOdología y FUENTES DOCUMENTALES}

Señalábamos al principio que resulta complejo saber qué es una relación de sucesos, y más delimitarlas como producto y género editorial, algo que no nos sucede respecto a los libros propiamente dichos. Sin embargo, tal y como apuntó Moll (1990: 206), hay un sinfin de impresos —entre los que se encuentran las relaciones- que no pueden ser considerados como libros porque constituyen otras formas editoriales con una personalidad propia. Lo cierto es que este estatus de forma editorial lo reúnen la mayor parte de las relaciones, pero el examen de cada edición debe realizarse sosegadamente y de forma minuciosa, puesto que, según Martín Abad, entre los quehaceres del bibliógrafo «la prisa es seguramente el peor enemigo» (Martín Abad, 1988: 278).

Resulta imprescindible que quien pretenda realizar un trabajo de carácter bibliográfico repose lo suficiente sus indagaciones y no caiga en la precipitación, ya que esto suele ocasionar que se tiendan a realizar juicios apriorísticos sin confrontar el mayor número posible de testimonios impresos antes de hacer cualquier afirmación. Debido a esto, no solo podemos encontrar descripciones defectuosas o incompletas, noticias bibliográficas mal construidas y las típicas noticias falsas, sino que también se realizan atribuciones que pecan de cierta endeblez, sin ir más allá del texto físico que tenemos delante de nosotros. Todo lo señalado cobra, además, una mayor importancia en el caso de las relaciones de sucesos, de ahí que sea necesario tanto un análisis como una lectura exhaustiva del continente y contenido de cada uno de estos impresos. Solamente así podemos llevar a cabo un ejercicio de bibliografia material sincero y honesto. 
Como sabemos, todo estudio de carácter bibliográfico debe aunar en el plano metodológico distintas facetas: primero, el examen in visu (o, en su defecto, a través de reproducciones digitales) de los ejemplares conservados en diferentes bibliotecas y, en segundo lugar, la consulta de documentación de archivo. En resumen, se trata de cruzar fuentes documentales con los impresos localizados, ya que solamente así podremos ir más allá de la historia externa para adentrarnos en esa historia interna de la que nos hablaba Infantes (2012: 137). Tanto es así que los entresijos de muchas ediciones se nos muestran indescifrables si nos detenemos en un estudio meramente material o bibliográfico, pues detrás del objeto en sí hay un sinfin de aspectos que se nos escapan, aunque podamos intuirlos. Esto nos obliga a rastrear los archivos en busca de testimonios que esclarezcan aquellos interrogantes que no somos capaces de responder a simple vista de forma certera y fehaciente. Los rastros documentales que podemos utilizar para reconstruir la Historia del Libro son muchos y variados, aunque, desde nuestro punto de vista, sean dos los más interesantes por la información que nos pueden aportar: la documentación procesal y las escrituras notariales.

No hay duda de que los pleitos dirimidos ante los Tribunales Reales arrojan un rico torrente informativo a partir de los interrogatorios que se llevaron a cabo durante los juicios, con lo que podemos conocer datos que nos remiten a circunstancias, costumbres o acontecimientos de vital interés para reconstruir el devenir de la industria editorial en cualquier parte de la Monarquía Hispánica y, más concretamente, en la Navarra del siglo XVII. En consecuencia, si nos detenemos en las ventajas que se derivan de su análisis como fuente documental podemos mencionar que:

a) Ayuda a vislumbrar de forma satisfactoria quiénes se encontraron detrás de la producción y comercialización de impresos en Navarra, desde los impresores hasta los buhoneros y ciegos copleros, pasando por libreros y mercaderes.

b) Permite descubrir ciertos impresos que nos eran desconocidos - ya que muchos no se conservan o no se han localizado todavía- gracias a referencias contenidas en pruebas periciales: declaraciones de testigos, inventarios de librerías, ejemplares de impresos, etc.

c) Esclarece el funcionamiento de todo el entramado administrativo que fiscalizaba la industria editorial en un reino tan pequeño como 
Navarra: petición de licencias y privilegios, aprobaciones, censura editorial, venta fraudulenta, etc.

d) Posibilita un mejor conocimiento tanto de la figura del editor como del autor — cuando no ejercía también como editor-, pudiéndose apreciar el protagonismo de ambos en el proceso de edición.

e) Favorece una comprensión óptima de los motivos reales que ocasionaron las denuncias que tuvieron lugar ante los Tribunales Reales en relación con la industria editorial.

f) Acerca a todo investigador a la práctica judicial, ya que las penas impuestas a los reos favorecen que se tenga constancia de la consideración social de los delitos y hasta qué punto los jueces siguieron los dictados de la legislación penal del reino.

Por todo lo reseñado, se debe considerar a las fuentes judiciales como un medio de un extraordinario valor para poder adentrarnos en los entresijos editoriales que nos evoca cada uno de los casos que fueron juzgados. Bien es cierto que cada pleito debe ser puesto en relación con la totalidad histórica, contextualizando y analizando cada suceso dentro de un todo mucho más amplio y complejo. No obstante, junto a los procesos judiciales otra de las fuentes más relevantes para conocer el mundo editorial durante el Antiguo Régimen es la documentación notarial.

Este género documental nos permite tener constancia de hechos muy sugerentes, pues no solo se trata de conocer los libros que fueron impresos, sino además las actividades comerciales de impresores y libreros. Es por esto que debemos destacar que las escrituras notariales, entre las que se recogen una riqueza documental muy excelsa, ayudan al investigador —como sugieren Ruiz Astiz (2018: 30-31), Pedraza (2008: 81) o Rojo Vega (1992: 425) — a adentrarse en una serie de aspectos que le facilitan la reconstrucción de un fenómeno tan complejo como el de la producción editorial.

El rastro dejado por este tipo de documentación en un sinfin de archivos nos ayuda a estudiar multitud de variables en torno al mundo de la imprenta en determinados espacios geográficos, lo que, a su vez, nos permite extrapolar situaciones concretas a las evidencias registradas en otros enclaves de la Monarquía Hispánica. Son muy variadas las ventajas que 
nos puede reportar el uso de documentación notarial, aunque entre las más relevantes cabría señalar las siguientes:

a) Testimonian actos entre distintas partes que nos ofrecen datos de vital interés para conocer diversas prácticas del mundo editorial, caso de los contratos de edición, la compra de materiales de impresión o los mandamientos de pago.

b) Aproximan al investigador a las relaciones familiares, sociales y mercantiles que mantuvieron los impresores y libreros afincados en Navarra con los profesionales asentados en territorios vecinos (Zaragoza, Logroño, Madrid, San Sebastián, Bayona, Pau o Burdeos).

c) Recogen la información necesaria para que podamos atisbar algunas de las pautas comerciales más usuales de la época, caso del flujo de noticias entre ciudades y su materialización en relaciones de sucesos.

d) Permiten reconstruir de forma fehaciente las modas editoriales, con lo que podemos ser conscientes no solo de los gustos en la lectura, sino además del funcionamiento del mercado.

e) Arrojan ricos testimonios sobre la percepción que tuvieron del negocio editorial los principales protagonistas -impresores, libreros, autores y editores - ante la proliferación de todo género de impresos.

A pesar de esto, tampoco debemos pasar por alto el hecho de que no siempre se escrituraron los acuerdos o negocios relacionados con la industria editorial, además de que no todas las escrituras se han conservado hasta nuestros días. Estos dos factores deben hacer que seamos cautelosos, ya que las fuentes accesibles puede que aporten una visión sucinta de lo realmente acontecido en un territorio concreto. Sea como fuere, no hay duda de que el uso de documentos notariales nos acerca al mercado del libro en distintas facetas, caso del conocimiento de las modas editoriales, las prácticas profesionales o las relaciones mercantiles, aunque por encima de todo cabe destacar la aproximación a la figura de todos aquellos personajes que se vieron envueltos en el fenómeno editorial durante aquellas centurias. Bien es cierto que, pese a su enorme valor, se hace imprescindible recurrir a otras fuentes que nos permitan una comprensión más certera del fenómeno editorial durante la Edad Moderna, puesto que se alcanzan 
conclusiones mucho más completas si se entrecruzan y fusionan distintos tipos documentales en investigaciones de esta naturaleza.

Tras advertir tanto las bondades como las limitaciones de los testimonios documentales — desde las relaciones de sucesos impresas hasta los documentos de archivo-, solo cabe afirmar que el trabajo bibliográfico para que resulte exitoso debe aunar, por un lado, la consulta de bibliotecas $y$, por otro, la de archivos. Esta es la única forma de que el resultado final sea lo más fiel posible a la realidad histórica, sin deturpar ni falsificar los entresijos editoriales que dieron lugar a los distintos ejemplares que hoy se acomodan en infinidad de bibliotecas.

\section{El protagonista: Martín de Labayen y su taller}

En 1600 nació en Pamplona uno de los impresores navarros más destacados del siglo XVII. Se trata de Martín de Labayen, quien muy probablemente aprendió el oficio en el taller de su hermano Carlos. Pese a esto, sabemos que Martín se formó como aprendiz con Nicolás de Asiáin, otro tipógrafo local ${ }^{2}$. Desconocemos los años que estuvo trabajando con él, aunque a buen seguro estarían comprendidos en la década de 1620, pues en 1622 figura con otros cuatros oficiales entre sus asalariados. No obstante, en torno a 1633-1634 habría comenzado su andadura en solitario como impresor, ya que en 1632 aparece comprando el utillaje del extinto taller de Matías Mares, que por aquel entonces lo poseía Juan de Oteiza.

Ese mismo año fallecía su hermano Carlos, por lo que pasó a competir por el mercado tipográfico pamplonés con su viuda - Felipa Rodríguezy su nuevo esposo: Domingo Vélez de Vergara. Si bien no fue una dura competencia, a lo que habría que añadir que en 1637 la viuda de su hermano le dejó en su testamento a su sobrina (Isabel de Labayen, hija de Martín) «dos formas de atanasia y una de letura» ${ }^{3}$. Dos años más tarde, en 1639 , compró una prensa, para lo cual tuvo que pedir un préstamo a Juan Morrás, dorador, por valor de 100 ducados. De este modo, el 15 de marzo

2 AGN. Tribunales Reales. Procesos, núm. 101627, fol. 11v.

3 AGN. Tribunales Reales. Procesos, núm. 31023, fol. 77v. 
suscribieron Martín de Labayen y su esposa, Ana Marrón, una escritura censal a favor de Morrás. En ella podemos leer:

Constituídos en persona Martín de Labayen, impresor de libros y Ana Marrón, su mujer, la cual con licencia y expreso consentimiento del dicho su marido que para otorgar esta escritura ella se la pidió y él se la dio y concedió en presencia de mí el escribano infraescripto de que doy fe y ambos a dos a mancomún en voz de uno y cada uno de por si et insolidum renunciando como renuncian la auténtica hoc hita, otorgan, conocer y confiesan recibir de manos y poder de Joan Morrás, dorador, vecino de esta dicha ciudad cien ducados en reales de a cuatro y de a ocho con obligación que hacen los susodichos de pagar en cada un año cinco ducados que la primera paga se ha de hacer a quince días de este dicho mes del año primero que viene de mil y seiscientos y cuarenta, se obligan e hipotecan el oficio de impresor como es todo género de los diferentes tocantes a la enprenta como son prensas, carates de letras y demás tocante al dicho oficio de enprenta y así se obligan la dicha Ana Marrón con su dote y conquistas y el dicho Martín de Labayen con su persona y ambos dos con todos los demás sus bienes muebles y raíces ${ }^{4}$.

La deuda fue saldada el 31 de mayo de 1646, cuando Morrás reconocía «estar satisfecho y pagado por entero de ello sin que se le deba cosa ninguna desde luego da por borrada y cancelada y por nula y ninguna esta escritura censal y da libres a las personas en ella obligados» $»^{5}$. Dos años antes, en 1644, Martín se hizo en propiedad con el otro taller de la ciudad, el que había fundado su hermano Carlos y que se encontraba regentado por Domingo Vélez de Vergara. De este modo, desde ese año, la imprenta pamplonesa estuvo monopolizada por Martín de Labayen. Un monopolio que perduró en el tiempo en manos de sus sucesores, hasta que en 1665 se dividió el negocio entre Isabel de Labayen — su hija, casada en segundas nupcias con Gaspar Martínez- y Martín Gregorio de Zabala — su nieto, e hijo de Diego de Zabala-.

Fueron, por tanto, unos 21 años (1634-1654) de una intensa actividad editorial, durante los cuales incluso llegó a conformar una sociedad con

4 AGN. Protocolos notariales. Caja 19118, Leg. 1, núm. 128, fol. 1r.

5 AGN. Protocolos notariales. Caja 19118, Leg. 1, núm. 128, fol. 3 v. 
Domingo Vélez de Vergara y Sancho de Istúriz, tal y como se constata por la escritura del 9 de julio de 1640. En dicha escritura de compañía podemos leer entre algunas de sus cláusulas el modo en que se iban a organizar el trabajo y, a su vez, las ganancias obtenidas:

Para que todos tres trabajen en el dicho ministerio de imprimir a medias y por iguales partes con las condiciones todas contenidas en la dicha escritura y partiendo aquellas entre los dichos tres compañeros por iguales partes en las ganancias que hubiere en las dichas emprentas y para los tiempos contenidos y expresados en la dicha escritura y so las penas en ella contenidas aplicadas conforme en ella está asentado y acordado así de las ganancias que tuvieren en imprimir en casa del dicho Martín de Labayen a donde más comodidad hubiere para el dicho efecto con que hayan de ser buenos, fieles y leales compañeros y no defrauden en interés alguno de un compañero al otro ni el otro algún otro, y porque el dicho Domingo Vélez de Vergara siendo así como es librero e impresor de libros y está admitido en la dicha compañía respecto de ser una de las imprentas que se ha de trabajar la dicha compañía suya a esta causa le dejan libre y quieren que consientan que sean suyas a solas las ganancias que el tuviere en cuanto toca al dicho oficio de la dicha librería y caso que trabajase y ayudase en el arte de la dicha imprenta le hayan de pagar la rata que le cupiere de las ganancias de lo que el trabajare los dichos Sancho de Istúriz y Martín de Labayen, y en demás a más de lo que tocare y perteneciere de su parte y porción de la dicha compañía que es de tres partes, una por el trecho de que está admitido en ella como dueño de la dicha enprenta de manera que si a uno de los dichos tres compañeros tuviere alguna enfermedad y no pudiere trabajar respecto de la indisposición que en este caso le hayan de acudir al tal con su tercera parte durante la dicha compañía como si trabajara y se hallare personalmente presente asistiendo a todos los dichos trabajos y con que todos los gastos, costas, daños y menoscabos que se ofrecieren los materiales, atreços, compras y todo lo demás adherente al dicho oficio o arte de imprimir sea por iguales partes a pérdida y ganancia sin otra excepción alguna y para así la guardar executar y cumplir todo lo contenido en esta escritura y la en ella alcançada ${ }^{6}$.

6 AGN. Protocolos notariales. Caja 19071, Leg. 1, núm. 57, fols. 1r-1v. 
La unión de los tres no duró más de 11 meses porque Istúriz no trabajaba en la imprenta pero sí atendía sus otros negocios (producción de aguardiente, entre otros), por lo que esta compañía cesó su actividad. Sin embargo, tanto Labayen como Vélez de Vergara siguieron por separado en sus respectivos talleres, más cuando ambos eran impresores del reino y de la ciudad de Pamplona. Así consta en distintos impresos, donde en el pie de imprenta podemos ver que Martín de Labayen se intitula de esa manera desde, por lo menos, 1635. Si bien a principios de 1642 ambos impresores sufrieron una reducción del salario que percibían del Ayuntamiento de Pamplona. Según consta por un acta del pleno celebrado el 26 de febrero de dicho año, se resolvió lo siguiente:

El que a los dos ympresores de la dicha ciudad se les vaje de su salario a cien reales y que assi como se les despachava libranças de duscientos reales a cada uno en cada un año, no se les despache de aquí adelante a más de a cien reales a cada ympresor, y que si alguno dellos no quisiere quedar asalariado por los cien reales quede un impresor tan solamente con duscientos reales ${ }^{7}$.

Este hecho habría empobrecido, más si cabe, el taller de Labayen, que no se caracterizaba — a tenor de una demanda que interpuso en 1645por ser muy boyante, ya que comprobamos, según las tasaciones que se hicieron entre noviembre y diciembre de ese año por Sancho de Istúriz y Pedro de Azcona, que contaba con dos prensas bastante envejecidas que estaban valoradas en 31 ducados, pues una tercera había sido vendida a Juan de Clavería. En lo que respecta al material de trabajo, aparecen mencionados «ocho manecillas de estaño que sirven de índice y apuntaciones en las márgenes de los libros», que empleaban los componedores para seguir el texto original; así como «frasqueta, ocho caballetes de madera, un banco grande que sirve para tener la tabla con el papel delante la prensa, dos componedores de hierro y ocho galeras de madera que sirven para poner las letras cuando se compone» ${ }^{8}$. Había, además, dos «matrices» tasadas en 16 ducados. Se reseñan, a su vez, cinco juegos de capitulares («abecedarios de letras floridas») de diversos tamaños, lo que condiciona en

7 AMP. Actas de Pleno, 1642, fol. 1r.

8 AGN. Tribunales Reales. Procesos, núm. 151540, fol. 44r-44v. 
buena parte su precio, ya que el de letra más pequeña se tasa en 23 reales mientras que la mayor, "once líneas de letra atanasia», vale 138. También figuran cincuenta letras de madera, de gran formato ("gran canon») valoradas en 6 reales, así como "una caxa de letras de parangona», "sesenta libras de letra de texto», «sesenta libras de letra de peticanon» o «una caxa de breviario»" entre otras muchas cosas.

Al margen de los utensilios, aparejos y letras de los que disponía su taller, sabemos que en 1643 enviudó de Ana Marrón y que ese mismo año su hija — Isabel de Labayen — se casó con el impresor Diego Zabala, a quien Martín de Labayen trajo desde Madrid, donde se había formado. El objetivo era doble; por un lado, entregarle el negocio a él dada su pericia y, por otro, reducir la carga de trabajo del maestro impresor en el taller porque su estado de salud había empeorado. Esto hace que desde 1644 podamos ver en el pie de imprenta sus nombres juntos en algunos impresos, pero no en todos ni mucho menos. Pese a esto, Martín de Labayen seguiría dirigiendo el negocio hasta su fallecimiento en 1654, tal y como lo demuestran los testimonios documentales conservados en algunos archivos.

De este modo, podemos rastrear su actividad como impresor independiente desde 1634 hasta 1654. A lo largo de estos 21 años publicó un total de 33 libros e impresos menores ${ }^{10}$, de los que 6 pueden ser considerados como relaciones de sucesos, aunque tal vez podamos llegar a añadir algún otro impreso en el futuro tras nuestras indagaciones en archivos y bibliotecas. Esto equivaldría a que un $18 \%$ serían textos de carácter noticioso, aunque si tenemos en cuenta solamente los impresos que publicó entre 1636 y 1648 este porcentaje aumenta hasta el 35\%. Pese a que este porcentaje no pueda ser considerado como definitivo, lo que deja entrever es que de su taller salieron puntualmente relaciones de sucesos. Además, si tenemos en cuenta los años de sus impresiones vemos que hubo momentos en los que los textos noticiosos tuvieron un destacado protagonismo entre los impresos que salieron de sus prensas: primero, en el período de 1636-1637; y, después, entre 1647-1648.

9 AGN. Tribunales Reales. Procesos, núm. 151540, fols. 33r-34v.

10 Pérez Goyena en su repertorio cifró su producción en 27, pero los hallazgos experimentados me permiten aumentar en 6 nuevos impresos sus apreciaciones. 


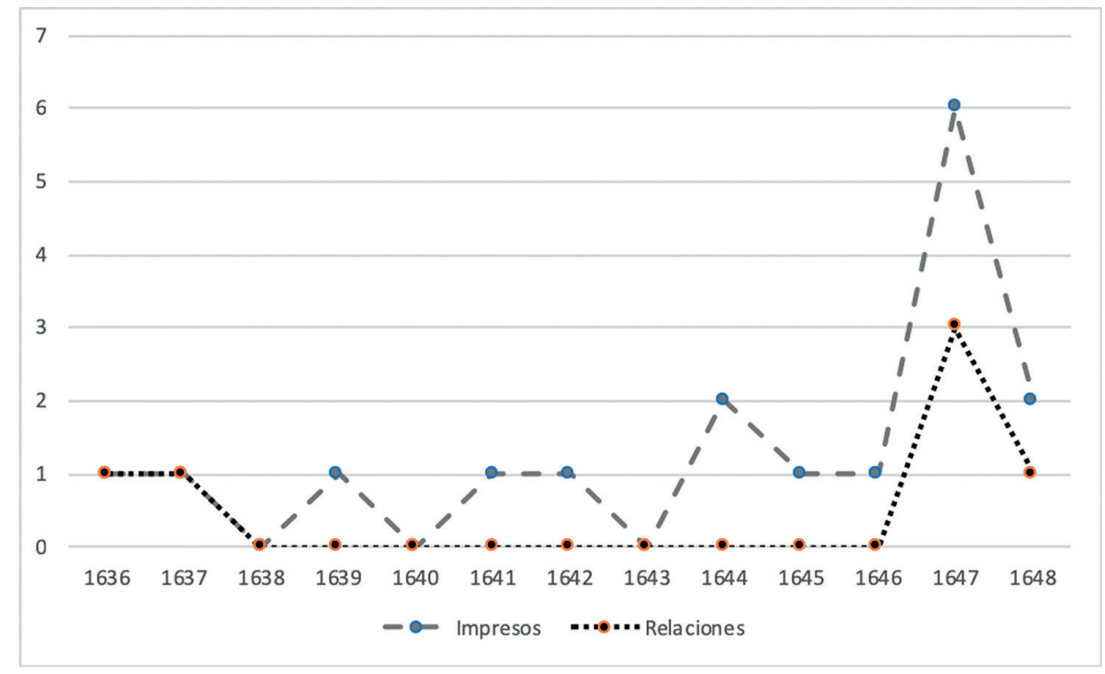

Gráfico 1. Relaciones de sucesos entre la producción editorial de Martín de Labayen (1636-1648)

En conjunto, se trató de un tipógrafo audaz y valiente que supo adaptarse a las circunstancias políticas, financieras y comerciales que le tocó vivir, manteniendo a flote su negocio en un contexto lleno de adversidades. Podríamos afirmar que, en cierta medida, consiguió reconducir la industria del libro en la Navarra del siglo XVII, abriéndose a nuevos productos y géneros editoriales. De todo esto, como veremos, dan buena cuenta las relaciones de sucesos que publicó en sus años como impresor.

\section{LA EDICIÓN DEL SUCESO Y SU INTRAHISTORIA}

Llegar a esclarecer la intrahistoria de cualquier edición resulta un trabajo laborioso y, hasta cierto punto, impredecible, al desconocer los testimonios documentales que pudieron existir y los que se conservan sobre ciertos impresos. Es tal su complejidad que, hace unos años, Moll (2011: 63) nos recomendaba desentrañar las relaciones tejidas entre impresores, autores y editores, ya que de esta manera seríamos capaces de conocer los distintos avatares por los que atravesaba una determinada obra antes de darla al público. Mucho más azarosos eran estos avatares si nos sumergimos en el rentable negocio de la información, ya que las noticias contenidas en 
las relaciones de sucesos eran consumidas tanto por la nobleza como por el vulgo. Su incontestable éxito radicó en el modo en que fueron transmitidas, pues circulaban de mano en mano y solían ser leídas en voz alta. Dado ese creciente interés que mostró la sociedad del Siglo de Oro hacia este tipo de productos es por lo que conviene que prestemos atención al papel ejercido por los promotores de tales impresos.

Sin embargo, descubrir la iniciativa editorial de cualquier impreso no siempre resulta sencillo. A veces son las portadas las que nos dan pistas sobre el costeador, quien habría ejercido de editor al sufragar su publicación. De esta manera, cuando aparece la expresión «a costa de» o «costeada por», cabe intuir la presencia de su editor. Lo habitual es que en las relaciones de sucesos no se indique el costeador, además, resulta sumamente dificultoso desentrañarlo cuando, en ocasiones, no tienen ni portada. Otras veces es el interior de algunas relaciones el que nos aporta información sobre la figura del editor.

Dicho esto, no son menos importantes ciertos testimonios documentales para llegar a reconstruir no solo las relaciones mercantiles características de la industria editorial, sino también la labor editora ejercida por ciertos sujetos - impresores, libreros y autores - u organismos institucionales — civiles y religiosos-. Aquí entran en juego, por ejemplo, los contratos de impresión, si es que se conservan o se suscribieron. De su análisis podemos entresacar valiosas referencias porque, además de mostrarnos la iniciativa editorial, conseguimos apreciar las exigencias estipuladas por los editores en el momento de suscribir dichos acuerdos.

No hay duda de que en 1647 publicaron conjuntamente Labayen y Zabala — gracias a la iniciativa de las Cortes de Navarra - la Ratificacion o iuramento que hizo el principe Don Baltasar Carlos heredero deste Reyno de Nauarra en presencia del Rey Don Felipe Sexto su padre en la Iglesia Catedral de la ciudad de Pamplona, y el que en sus reales presencias prestaron a su Alteza los tres Estados deste Reyno, junto en sus Cortes generales, el año 1646. En este impreso se relata minuciosamente todo el protocolo seguido en la jura del hijo de Felipe IV —fallecido cinco meses después en la vecina Zaragoza-, así como los asistentes que juraron al príncipe heredero. No deja de ser curioso que, aun sabiendo la muerte del próximo monarca, las instituciones locales decidiesen seguir con este proyecto editorial. Sin embargo, lo que pretendía poner de manifiesto el Reino y las Cortes con 
este texto es la aceptación de los Fueros de Navarra por parte no ya del heredero, sino implícitamente del monarca reinante.

Otro impreso de 1647, esta vez promovido por el cabildo catedralicio o el obispado de Pamplona, sería la Carta del ilustrissimo y reuerendissimo señor don Iuan Queipo de Llanos y Valdès, Obispo de Jaén, del Consejo de su Magestad, Ec. Escrita a su ciudad y mandada imprimir cõ su inclusa por el señor D. Alonso Fernãdez de Henestrosa, Cavallero del Abito de Alcantara, señor de la villa de Teva. Un texto donde el saliente Obispo de Pamplona - Juan Queipo de Llano - avisa a Jaén de su próxima llegada a la ciudad jienense, además de informar de algunos hechos que acontecieron en 1646 durante la estancia del rey y el príncipe en Pamplona, junto a una somera descripción de las tierras que conforman el obispado pamplonés. De este modo, esta relación habría sido encargada al taller de Labayen, ya que, aunque obvia el nombre del impresor, el hecho de que la daten en Pamplona junto a las características materiales de la letrería empleada en su confección nos lleva a asignarla a dicho tipógrafo.

Pero no siempre nos topamos con impresos financiados por instituciones civiles y religiosas, sino que aparecen otros textos editados por sus propios autores o en unión con algún impresor. Este es el caso de una relación en verso que se editó en honor a la victoria de las tropas navarro-guipuzcoanas en Fuenterrabía en 1638. Sabemos que este suceso provocó la impresión de multitud de relaciones que narraban el acontecimiento ${ }^{11}$. Entre todas estas encontramos el relato poético que compuso Diego Felipe Suárez, beneficiado de Falces, donde loaba el papel y ardor de los navarros en su Triunpho de Navarra y vitoria de Fuenterrabia. En este caso, pese a que tenemos la mención de autoría, cabe pensar que la iniciativa sería compartida entre el autor y Martín de Labayen, quien aparece en el pie de imprenta tras el título, aunque no tenemos más datos para refutarlo.

No obstante, no cabe duda de que quienes promovieron con mayor interés la edición de relatos noticiosos fueron determinados impresores, pues eran perfectos conocedores del auge y éxito editorial de estos impresos, por lo que no dudaron en ejercer como promotores de tales textos. En muchos de estos casos, sobre todo cuando el autor no estaba

11 Así lo ha demostrado en su estudio Díaz-Noci, 2003. 
detrás de la edición, apreciamos a los impresores transcribiendo a la letra las comunicaciones recibidas, bien fuesen éstas manuscritas o impresas. Asimismo, hubo casos de tipógrafos que construyeron los relatos informativos a partir de diferentes fuentes — cartas, avisos u otras relaciones-, por lo que realizarían también labores de recopilación, orden y redacción de la noticia.

Desentrañar estos aspectos es lo que se conoce como la historia interna de cualquier edición, gracias a la cual podemos esclarecer datos sumamente reveladores sobre los entresijos de muchas relaciones de sucesos. Esto cobra más relevancia si cabe al plantear la siguiente cuestión: ¿sabemos siempre quién redactó una información y cómo fue el proceso de composición de una relación? A simple vista puede que sí, pero la realidad es mucho más compleja e intrincada de lo que pueda parecernos. Así, por ejemplo, en 1645 sabemos que apareció impresa en Logroño la Relacion de la memoria funeral que en 27 y 28 de Noviembre de 1644 la muy noble y muy leal ciudad de Logroño hizo a la muerte de la catolica D. Isabel de Borbón, escrita por José Esteban Ximénez de Enciso y Porres. El nombre que figura en el pie de imprenta es el de Juan Díez de Valderrama. Sin embargo, éste no ejecutó el trabajo en su totalidad, pues sabemos que Martín de Labayen también habría participado en su publicación junto al impresor riojano ya que en 1649 le solicitaba una deuda por valor de 60 reales a Díez de Valderrama. Así en un poder suscrito el 19 de septiembre de dicho año por Martín de Labayen, en favor de Diego de Zabala (su yerno), se indicaba:

Constituidos en persona Martín de Labayen, impresor vecino de esta ciudad y dixo que por ocupaciones que tiene no puede ir a la ciudad de Logroño a recebir y cobrar de Juan Díez de Valderrama, así bien impresor vecino de la dicha ciudad de Logroño sesenta reales en plata que le quedó debiendo de resta de cien reales de haber trabaxado en cierta obra que se hiço para las honrras de la reyna nuestra señora, por tanto, certificado de todo su buen derecho por esta presente carta y su tenor dixo daba todo su poder cumplido y el que de derecho en tal cosa se requiere y más puede dar y valer y sin limitación alguna a Diego de Çabala, así bien impresor, su yerno, que está presente y aceptante para que en nombre del otorgante y representando su propia persona pueda haber recebir y cobrar del dicho Juan Díaz de Valderrama los dichos sesenta reales en plata y de lo que así recebiere y cobrare pueda dar y de su carta o cartas de pago haga fin y 
cuenta y pereciendo la entrega de presente raçon hiciere y no pareciendo pueda renunciar y renuncie a las leyes de la entrega, paga y prueba ${ }^{12}$.

Como puede verse, solo si tratamos de despejar las dudas en torno a la figura del editor en los siglos modernos podremos mejorar nuestro conocimiento sobre la iniciativa editorial de algunas de las relaciones de sucesos que se conservan en bibliotecas y archivos.

De este modo, lo que apreciamos es que Martín de Labayen mostró cierta predilección por la edición de textos noticiosos, pudiéndole atribuir, casi con total certeza, la iniciativa editorial en tres relaciones de sucesos (Ruiz Astiz, 2019: 29); una de 1636 (Relacion verdadera del sucesso de la toma de Andaya, Uruña, Ciburu, San Juan de Lus y el Puerto y fuerça de Zocoa en Francia, hecha por la gente del reyno de Nauarra, y prouincia de Guipuzcoa ${ }^{13}$ ), otra de 1647 (Carta escrita por un caballero aragones, en que da cuenta a un amigo de Pamplona de lo sucedido en Barcelona, y sitio de Lerida, y de la revolución que passa en Paris de Francia) y, la tercera, de 1648 (Relacion del feliz sucesso que tuvo don Juan de Austria en la ciudad de Napoles).

A su vez, cabe pensar que posiblemente se encontró detrás de dos relaciones más; por un lado, Relacion de lo que ha pasado, y passa en la ciudad de Pamplona, sobre los encuentros de Virrey, y Consejo con el Obispo de la dicha ciudad sus ministros, y demás clérigos, y por el otro, Relacion del festejo, alegría y lucimiento con que la ciudad de Pamplona celebró el nacimiento del Ilustrísimo Sr. D. Joaquín de Portugal, marqués de Jarandilla. Las dos fueron referenciadas por Pérez Goyena ${ }^{14}$, fechándolas en 1636 y 1644 respectivamente, pero sin advertir el nombre del tipógrafo. Nuestra intención es poder encontrarlas, ya que la localización que indica en su repertorio para ambas es inexistente en la actualidad, lo que ha provocado que todavía no hayamos podido dar con ellas aun con los intentos efectuados. Sin embargo, creo firmemente que estas dos relaciones pudieron salir del taller de Martín de Labayen, algo que haría que aumentásemos su producción

12 AGN. Protocolos notariales. Caja 19100, Leg. 2, núm. 463, fol. 1r.

13 Sobre esta relación y la repercusión editorial que tuvo puede consultarse el trabajo presentado en el IX Coloquio de la Sociedad Internacional para el Estudio de las Relaciones de Sucesos celebrado en Rennes en septiembre de 2019. Véase Ruiz Astiz (En prensa).

14 Se trata de las noticias bibliográficas 484 y 520, respectivamente. Consúltese Pérez Goyena, 1947, vol. II. 
en dos nuevos impresos. Cierto es que todo esto son solo especulaciones e intuiciones librescas, ya que resulta imprescindible localizar estos textos y, después, proceder a su examen material para poder realizar una atribución fidedigna.

A pesar de lo señalado hasta ahora, tampoco podemos considerar a Martín de Labayen como un impresor preocupado por editar preferentemente este tipo de productos. Se trataría de un tipógrafo que, de forma esporádica, se embarcó en la publicación de relaciones de sucesos movido por intereses comerciales, pues no debemos olvidar que los papeles noticiosos eran más sencillos, rápidos y baratos de confeccionar si los comparamos con otro tipo de impresos. Ese posible beneficio económico debió de ser el motor principal que inspiró la edición de distintas relaciones que publicó en su taller.

Dicho esto, llama la atención que entre 1647 y 1648 editase dos relaciones relativas a sucesos acontecidos en Cataluña, París y Nápoles, ya que altera la práctica habitual de sus impresos anteriores, que versaban sobre acontecimientos cercanos tanto por la distancia geográfica como por la implicación del reino. Esto podría venir a corroborar la idea de que existía un flujo de noticias que llegarían hasta Pamplona desde otros rincones peninsulares, tejiéndose así una red de informantes que podría ir desde el Mediterráneo hasta el Cantábrico, saliendo desde Barcelona y llegando hasta San Sebastián, previo paso por Zaragoza y Pamplona ${ }^{15}$. El hecho de que Martín de Labayen editase relaciones sobre temas ajenos al reino de Navarra nos invita a pensar que tuvo que tener algún contacto en una ciudad próxima que le suministrase la información. Este aspecto tan interesante está pendiente de esclarecer, aunque, por los datos recabados, tengo la intuición de que Zaragoza pudo ser ese foco difusor de impresos y avisos manuscritos que suministró a Martín de Labayen novedades para luego llevarlas a sus prensas.

Las relaciones comerciales entre ambas ciudades debían ser sumamente estrechas y vendrían de tiempo atrás, ya que en 1637 tenemos constancia de que Martín de Labayen suscribió una obligación en favor de Bernardo de Eguiarreta, arrendador de las tablas reales de Navarra. ¿El motivo?

15 Este nudo comunicativo tejido de Este a Oeste entre Barcelona y San Sebastián ha sido insinuado recientemente en un trabajo de Díaz Noci, Espejo y Baena (2018). 
Parece ser que Joan de Enciso, librero afincado en Tudela, se quejó porque el 11 de julio «las guardas de la ciudad de Tudela le han descaminado dos balas y un paquete de libros y diez varas de paño, siete de paño n los tres de color remitidos por Pedro Ezquer, mercader de libros de la ciudad de Çaragoça, para Martín de Labayen, impresor de libros». Este último para saldar lo adeudado a Eguiarreta y recuperar así los libros remitidos por Pedro Escuer (o Ezquer) desde Zaragoza «se obligaba y obligó con su persona, bienes así muebles como raíces de sacar y de me pagar y a salvo de esta fiança al dicho su fiador (Joan de Enciso) y ambos a dos se obligan sus personas» ${ }^{16}$. Vemos, por tanto, que entre Pamplona y Zaragoza se intercambiaban impresos de todo tipo, por lo que muy posiblemente habría entre ellos relaciones impresas e, incluso, avisos o cartas manuscritas dando cuenta de novedades en otras partes de la Monarquía Hispánica. La diferencia estriba en que Labayen decidió editar algunos textos, pero a buen seguro que tuvo constancia de más hechos que no quiso publicarlos en forma de relación de sucesos.

En suma, lo que constatamos es que la edición de relaciones de sucesos fue promovida por distintas figuras, desde autores hasta impresores, pasando por instituciones civiles y religiosas. Por desgracia, como hemos señalado, si nos conformamos con la historia externa de los impresos no obtendremos un conocimiento pleno de la realidad editorial, por lo que debemos tratar de descubrir, siempre que se pueda, esa historia interna que está oculta a simple vista y de la que puede seguirse la pista en distintos archivos. De este modo, solo tratando de despejar las dudas en torno a la figura de la edición en los siglos modernos mejoraremos nuestros conocimientos sobre las peculiaridades específicas de un producto editorial tan complejo como las relaciones de sucesos.

TeXtos NOTICIOSOS EN LA IMPRENTA: TIPOS, CLASES Y CARACTERÍSTICAS

No hay duda de que la imprenta de Martín de Labayen fue una de las más destacadas en la Pamplona del siglo XVII, siendo equiparable en cuanto a la calidad de sus textos y a la ambición mostrada como tipógrafo a la que alcanzaron antes su hermano Carlos o Nicolás de Asiáin, y a la

16 AGN. Protocolos notariales. Caja 18956, Leg. 1, núm. 160, fol. 1r. 
que tendría después su nieto Martín Gregorio de Zabala. Pese a ser una figura de gran calado a nivel local, resulta evidente que los textos que publicó Labayen a lo largo de 21 años destacaron por la sobriedad, el uso de tipos desgastados y la escasa ornamentación, aunque se aprecia el gusto por las portadas decoradas con escudos. Este modo de proceder sería seña de identidad de su taller, algo que podemos rastrear a través de las distintas relaciones de sucesos que salieron de sus prensas.

Como hemos advertido antes, en total podemos atribuirle a su taller 6 textos noticiosos, aunque entre 1647 y 1648 dos de los cuatro impresos que podríamos considerar como relaciones de sucesos ni mencionan el nombre del impresor. Sin embargo, considero que deben ser atribuidos a este taller porque tras un análisis y estudio material pormenorizado llego a esa conclusión. Esto es posible porque, tal y como sugirió Moll, «es uso largamente aceptado el estudio y análisis de los tipos empleados por los impresores para intentar la atribución de los libros sin indicaciones tipográficas» (Moll, 1988: 295). En nuestro caso el uso de las capitulares y de otro tipo de iniciales, así como de portadas repetidas, hace que las atribuya al taller de Martín de Labayen, aunque puede que quien estuviese en aquel entonces ejerciendo como impresor titular fuese Diego de Zabala. Como podemos apreciar por las imágenes 1 y 2, las portadas son coincidentes, aunque en la segunda no aparezca el nombre del impresor en el pie de imprenta. Sin embargo, si vemos la imagen 3, donde aparece una capitular con la letra «D»y la comparamos con la muestra de capitulares de la imagen $4^{17}$, en concreto con la «M»y «C» que aparecen en la cuarta fila, constatamos que procedían del mismo taller. Por tanto, tal y como se comprueba, el impreso de 1648 que versa sobre los sucesos acaecidos en Nápoles puede ser asignado sin temor a equivocarnos al taller de Labayen.

Sabemos, como nos advierten Corbeto y Garone, que la resistencia de las matrices permitió que «si se conservaban de forma adecuada, se podían reutilizar múltiples veces y a lo largo de muchos años» (Corbeto y Garone,

17 Esta muestra se recoge en el pleito que mantuvieron Gaspar Martínez y Martín Gregorio de Zabala en 1676, donde se insertan como pruebas periciales juegos de matrices de letras capitulares e impresiones procedentes del taller de Martín de Labayen y Diego de Zabala. AGN, Tribunales Reales. Procesos, núm. 179919, fol. 192r. 
2015: 73). Esto lo podemos apreciar en los impresos que salieron de las prensas de Labayen entre 1636 y 1648, donde se constata principalmente la reutilización de las mismas letras: parangona y atanasia. Junto a esto, los seis impresos que consideramos, con total seguridad, que salieron del taller de Martín de Labayen reúnen una serie de características bastante comunes o reiterativas. Todos son textos breves en cuanto a su extensión ${ }^{18}$, aunque el formato oscila entre el folio y el $4^{\circ}$, donde hay tres para cada uno de ellos.

Por otro lado, cuatro van precedidos de una portada, mientras que los dos restantes tras el título del impreso disponen el texto en prosa y verso. Lo curioso es que Labayen cuando decidió recurrir a una portada previa empleó siempre el mismo modelo a la hora de disponer la información: enunciado del impreso, escudo de Navarra o de la Monarquía Hispánica $y$, tras esto, el pie de imprenta ${ }^{19}$. Llama la atención que, incluso, replicó un mismo modelo de portada, tal y como podemos apreciar en las relaciones de 1647 (Carta escrita por un caballero aragones, en que da cuenta a un amigo de Pamplona de lo sucedido en Barcelona, y sitio de Lerida, y de la revolución que passa en Paris de Francia) y 1648 (Relacion del feliz sucesso que tuvo don Juan de Austria en la ciudad de Napoles), al emplear el mismo escudo xilográfico.

A su vez, en el título vemos cierta heterogeneidad, con la expresión relación y carta en cuatro ocasiones, y en las restantes se emplearon otras formas de enunciar el impreso. Por último, cabe mencionar que la licencia es advertida en 2 impresos —ambos de 1636 y 1638 - aunque ninguno de ellos la contiene al ser inexistentes los paratextos legales ${ }^{20}$. Vemos, por tanto, que la Pragmática de $1627^{21}$ se cumplía de una manera particular, pues si bien algunos impresos recogen la mención al lugar y la fecha de edición, así como al nombre del impresor - y al autor siempre que sea

18 Entendemos por relaciones breves, siguiendo a Fernández Valladares (1999: 110), las que conjugan su formato con una determinada extensión: $4^{\circ}$ (24 hojas o 48 páginas), $8^{\circ}$ (16 hojas o 32 páginas) y Folio (8 hojas o 16 páginas). En consecuencia, todas aquellas que excedan dichos límites deben ser consideradas como extensas.

19 Esto se comprueba en las imágenes 1, 2 y 5.

20 Esta práctica, sobre todo en las relaciones breves, parece que era la tónica habitual, tal y como lo ha advertido recientemente Martín Molares, 2017: 374.

21 Véase la magnífica recopilación de textos legales efectuada por Reyes Gómez (2000). 
distinto del propio impresor-y la mención a la licencia, otros muchos no cumplen con estas indicaciones en su totalidad.

Todas estas peculiaridades materiales (tipografia, formato, composición, etc.) hacen de las relaciones impresas por Martín de Labayen un producto editorial prototípico dentro de la vasta producción de textos noticiosos que tuvo lugar en la Península Ibérica en la primera mitad del siglo XVII. Asimismo, como no podía ser de otro modo, el hecho de que del taller de Labayen salgan relaciones de sucesos entre 1636 y 1648 —en plena Guerra de los Treinta Años-, explica que mayoritariamente versen sobre acontecimientos político-militares, pues tan solo dos tratan sobre el juramento del príncipe heredero en 1646 o la visita de Felipe IV y otros aspectos relacionados con el obispado pamplonés. De esta manera, son cuatro las relaciones que se publicaron en Pamplona sobre la guerra abierta en Europa por aquellas fechas, en las cuales se nos da cuenta de campañas militares como las de Labourd en 1636 o Fuenterrabía en 1638, así como sucesos alejados de las fronteras navarras, caso de las contiendas catalana y napolitana, que vieron la luz en 1647 y 1648.

Trazado someramente todo este panorama, y a modo de resumen, podemos considerar que la producción editorial del taller de Martín de Labayen reúne los elementos básicos del contexto histórico que le tocó vivir. Así apreciamos que sus relaciones de sucesos, entendidas como producto, solo se entienden desde un prisma de precariedad y escasez monetaria, lo que explica que su producción sea sobria y descuidada en lo material, algo que fue bastante usual en aquella época y más para editar este tipo de impresos. A su vez, la coyuntura bélica experimentada durante sus años de impresor condicionó, en buena lógica, las noticias que decidió componer, y más cuando todo tipógrafo se debía a la demanda lectora. En suma, detrás de todo esto nos encontramos el deseo de rentabilizar una inversión financiera, de ahí que no se preocupase sobremanera por la calidad material de los textos y acometiese la edición de relaciones de temática militar. 
CARTA ESCRITA POR VN CA VALLEROARA. gores, en que da cuenta a vn amigo de Jamplona de lo rucedido en Barcelcna, y fitio de Lerida, y de la reuolucion que pafta en Patis de Francia.

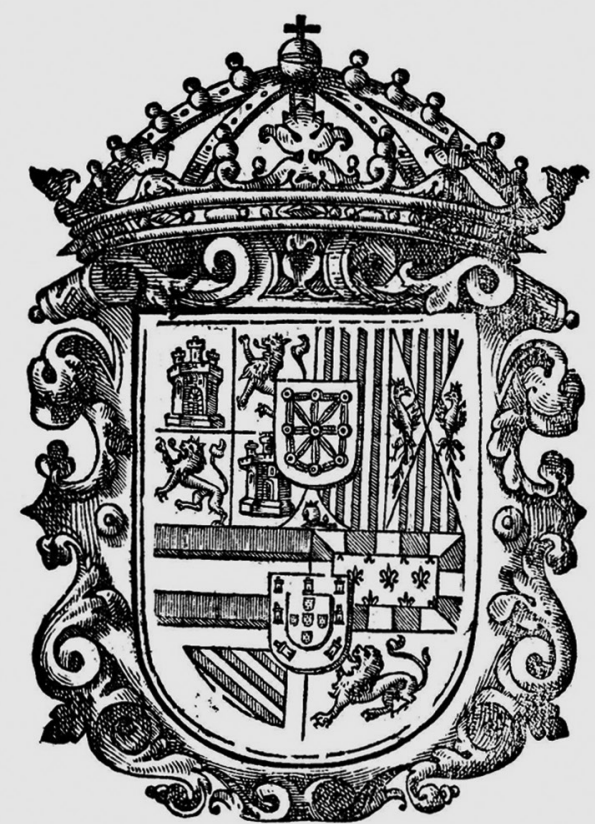

En Pamplona, por Martin de Labayen. Año 1647 i

Imagen 1. Portada de 1647 


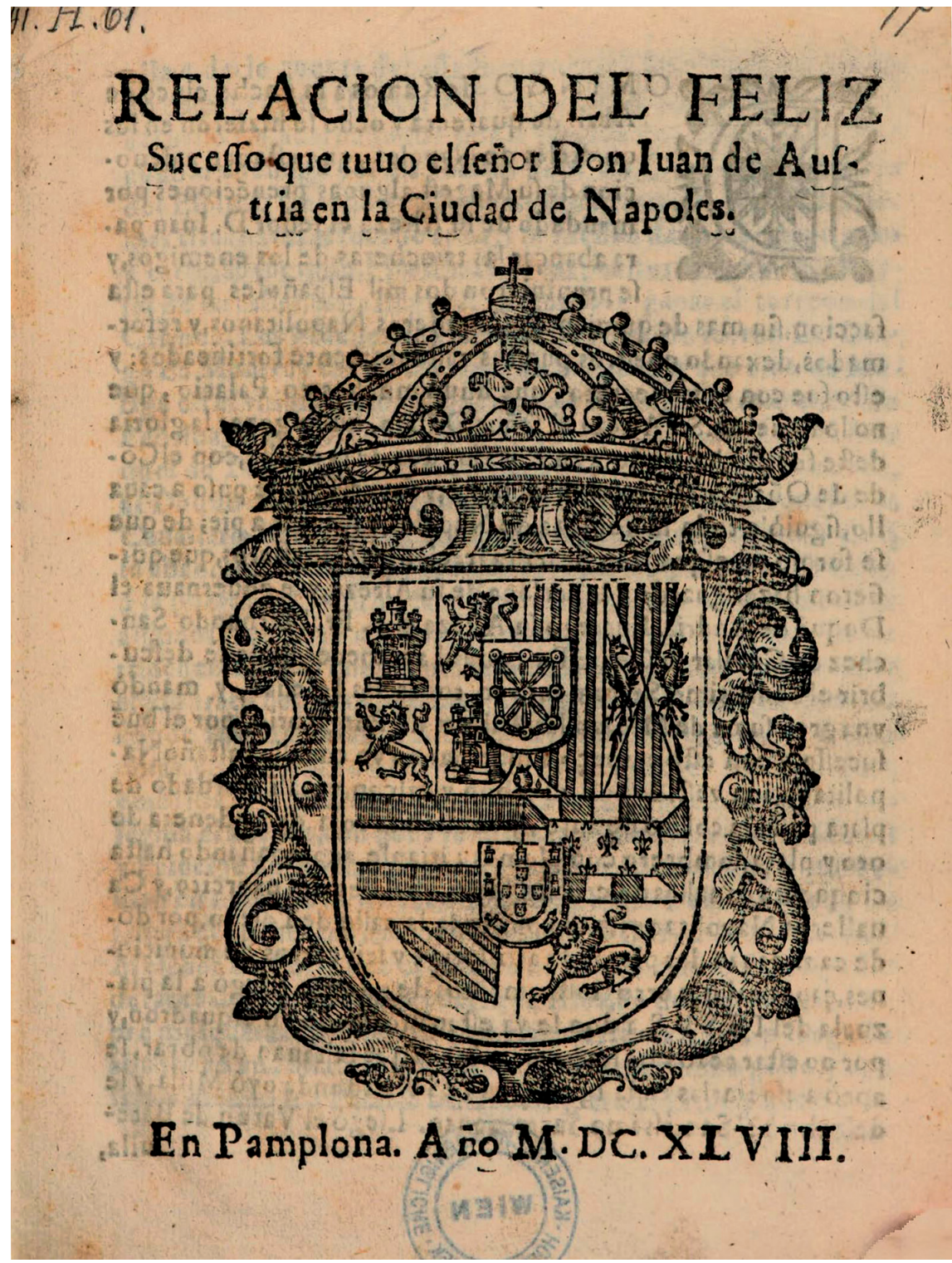

Imagen 2. Portada de 1648 


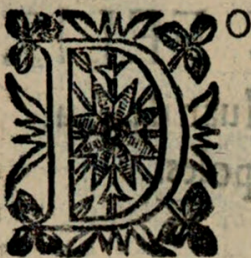

MIN GO de Ramósala boche ciocode Abril de quarecita y ocho fe hizieron en los quarteles de Napoles, que efta uas a devo. cioa de fu Magett.algunas preuēciones pos iundado de fu Alieza el feńor D. luan pa. ra abauçar las triocheras de los enemigos,y fe preuinieron dos mil ECpañoles para efta faccion, fia mas de quíaiencos Cauallecos Napolitanos, y reformados, dexado nueftros pueitos vaftantemente fartificados: $y$ elto fue con tanco fecreco, que huuo machos en Palacio, que no lo fupieron. Su Alceza el feñor D. luan, quilo gozarla gloria defte fuceffo, hallandoféen el: $r$ a las dos de la noche, con elCó. de de O hate, y D, Melchor de Borja,y fas criados, fe pufo a caua Ilo,figuiòle coda la nobleza de Napoles,y los mas a pie; de que fe formò vo efquadron de hafta trecientos. Saualleros, que quifieron bazer guarda a la perfona de fu Alreza, y le goureroaua el Duque de Andria. Encargò fa Alieza al R. Fr. Heroando San. chez de Cuellar fu Confeifor, que al amanecer hizieffe defcu. brir el Santilsimo Sucramebcoen todas las Iglefias, y mandò va a gran fuma de Milias a las Animas de Purgacorio, por el bue Lucello, y con efto empeçò a marchar en vo cauallo caltuńoNa. polisano,iua veftido con va jubon y calçon, y taàli bordado de plata paffada coleto de ante, y va banda roja de cadenera de oco y placa, fombrero con plumas; iriaule acompańando hafta ciaquenca cauallos de criados fuyos, oficiales del exorcico,y $\mathrm{Ca}_{\mathbf{a}}$ ualleros Napolitanos, pafló por to ja la calle de Toledo, por dō. de caminaua dos pieças de arcilleria , y feis carros de municio. nes,çapas,palas,y ocrosinitrumeocos de guerra. Llegó a la plazuela del I ES V S, a doa je ya eftuua formado vn efquadron,y poc no eftac acaba las las pecuenciones que fal taua de obrar, fe apeò a elperarlas en la lglefia del IESV j,adonde oyó Milla, y fe

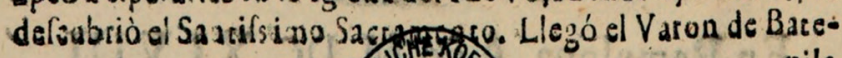

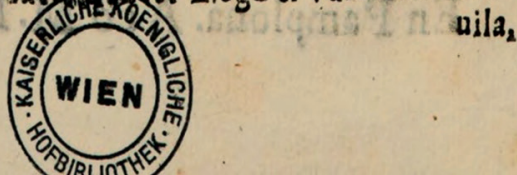

Imagen 3. Letra capitular de la relación de 1648 


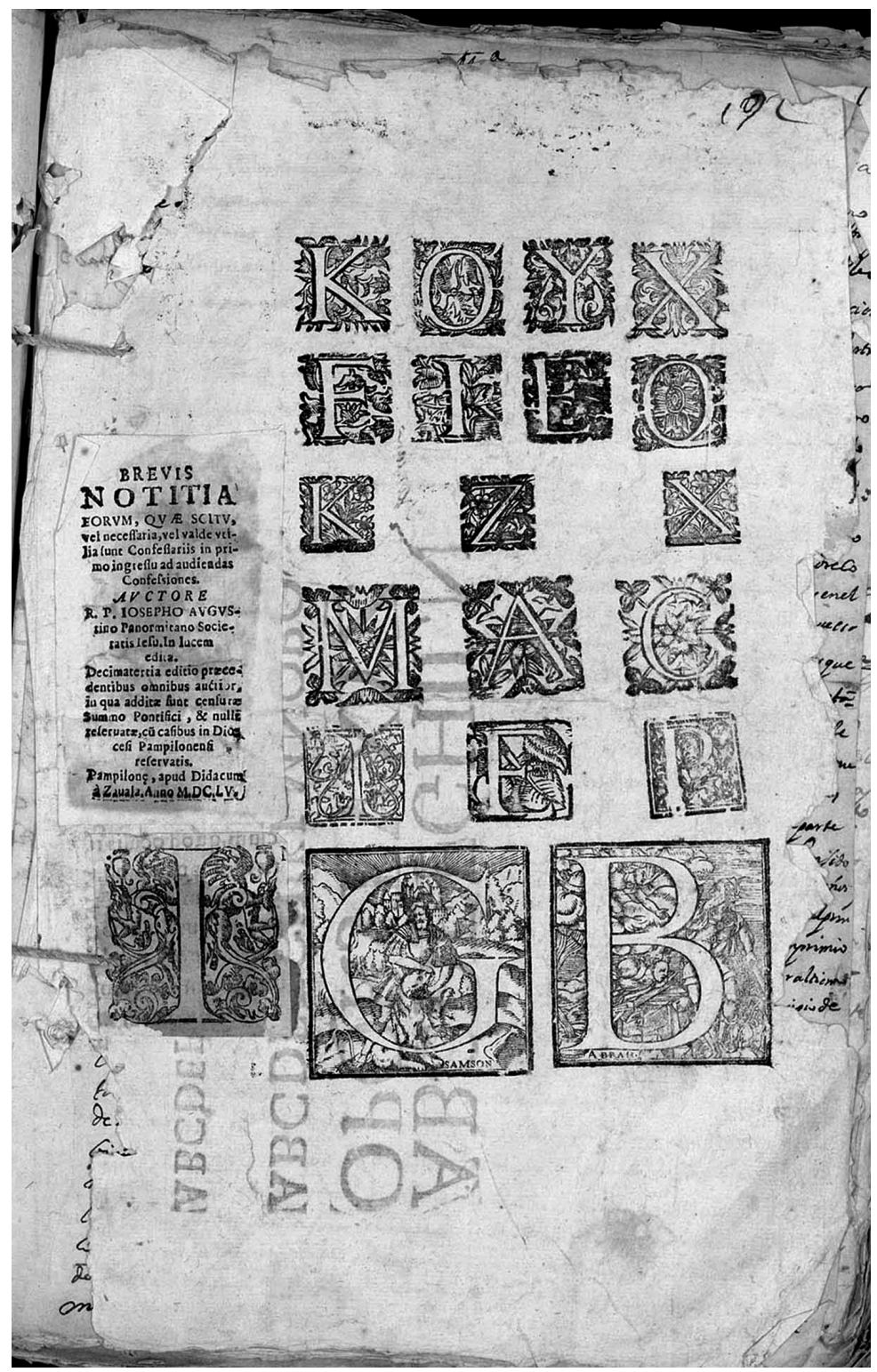

Imagen 4. Muestra de letras capitulares del taller de Martín de Labayen 


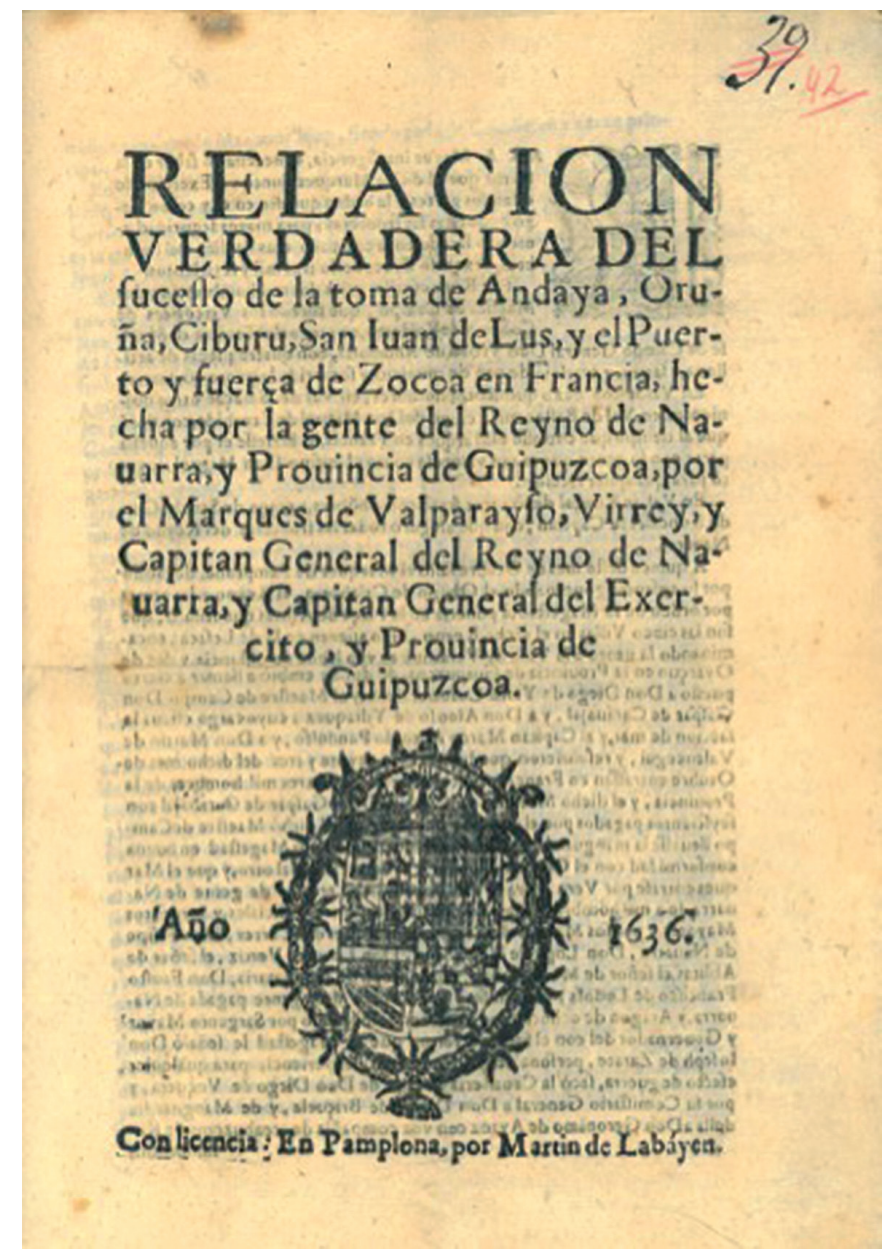

Imagen 5. Portada de 1636 


\section{EPÍLOGO: LOS PAMPLONESES DEMANDAN RELATOS NOTICIOSOS}

Durante el siglo XVII los impresores afincados en Pamplona, a pesar de la sobriedad de la mayoría de sus impresos, abrieron su negocio a la llegada de nuevos productos editoriales que introducir en el mercado local. Entre todos estos podemos entresacar las relaciones de sucesos, las cuales se erigieron, a tenor de los textos editados en la capital de Navarra, en un tipo de impreso que gozó de cierta demanda entre los lectores pamploneses. Cierto es que las relaciones se editaron, mayoritariamente, en momentos puntuales, aunque en la primera mitad de esta centuria registramos un impreso noticioso cada dos años. Esta pauta, sin embargo, decayó en las siguientes décadas, cuando se publicó una relación cada cinco.

Este hecho, lo que pone de manifiesto, es que los tipógrafos del reino no fueron ajenos al éxito experimentado por las relaciones de sucesos, pues como expuso Ettinghausen (2015), se trató de un fenómeno paneuropeo. No obstante, resulta evidente que el consumo local no sería suficiente para hacer rentable un producto que, aun siendo barato, reportaba unos réditos financieros considerables. Sin duda, estoy convencido de que la reducida capacidad de demanda del mercado navarro - en lo que al número de potenciales lectores se refiere- provocó que Pamplona no pueda ser considerada una urbe de cierto potencial en la publicación de relatos noticiosos. Esa realidad se debió, en gran medida, a las dificultades que introdujo en 1558 la Pragmática de Felipe II, ya que prohibía que los impresos navarros circulasen con total libertad por los reinos de Castilla y de la Corona de Aragón, lo que habría ahogado la iniciativa editorial y las ansias comerciales de los impresores afincados en el reino de Navarra. A esto tendríamos que unir la Pragmática de 1627, en la que se establecía la obligatoriedad de indicar en las relaciones impresas la fecha y el lugar de edición, además de referenciar el nombre del impresor y del autor.

Sin embargo, pese a las dificultades advertidas, las primeras décadas del XVII coinciden con la presencia de importantes talleres de imprenta en la capital del reino, algo que pudo motivar una mayor presencia de tales impresos en las prensas pamplonesas. Asimismo, el hecho de que algunos de ellos fueran coetáneos en el tiempo habría provocado que, ante la mayor competitividad en un espacio tan limitado, se viesen avocados a publicar nuevos productos editoriales, como es el caso de las relaciones de sucesos. 
En este contexto debemos ubicar la figura de Martín de Labayen, quien no solo se aventuró a publicar este tipo de producto editorial recogiendo relatos íntimamente relacionados con Navarra, como solía ser lo habitual, sino que también se atrevió con noticias que procedían de zonas alejadas del reino, como la guerra de Cataluña, la Fronda parisina o la revuelta napolitana. Esto nos habla, bien a las claras, de la inquietud de un impresor local por acercar las novedades que se estaban produciendo en otras partes de Europa a los lectores navarros. Por tanto, el papel que desempeñó como editor ha quedado patente, puesto que estuvo detrás de la publicación de cuatro relaciones, aunque también es cierto que en otras dos ejerció meramente como impresor porque fueron sufragadas por instituciones civiles (el Reino o las Cortes) y religiosas (el obispado pamplonés).

Sea como fuere, de las prensas de Martín de Labayen salieron seis relaciones de sucesos — aunque puede que sean hasta ocho a falta de dar con las ediciones que no se han podido localizar-, lo que pone de manifiesto que en la Pamplona del siglo XVII se imprimió este producto editorial. Esto evidencia, sin ninguna duda, que la demanda lectora local no se limitó a consumir los textos que procedían de distintos talleres peninsulares o de otras partes del continente europeo, sino que podemos apreciar cómo brotó entre los navarros un interés, preferentemente, por los acontecimientos políticos, militares y festivos acontecidos en el reino y fuera de él.

Ante tal situación, no resulta sorprendente que algunos tipógrafos decidiesen publicar noticias de toda índole de manera puntual. Algo que, a su vez, nos permite constatar que Navarra también se sumó a ese circuito ávido de noticias que se tejió por toda la Europa occidental, si bien su incidencia fue testimonial si se compara con otros territorios. No obstante, lo realmente importante es que esta realidad refleja la llegada a Pamplona y al resto del reino de las modas editoriales que se asentaban en los principales focos impresores del continente.

\section{BiBLIOGRAFÍA}

Arigita, Mariano, Bibliografía navarra o descripción de las obras impresas en este antiguo reino desde el descubrimiento del arte tipográfico hasta nuestros días, Pamplona, Imprenta Provincial, 1901. 
Corbeto, Albert y Marina Garone, Historia de la tipografía. La evolución de la letra desde Gutenberg hasta las fundiciones digitales, Lleida, Milenio, 2015.

Díaz Noci, Javier, «Del suceso a la fiesta. La construcción del acontecimiento en el Siglo de Oro español a través de las relaciones sobre el sitio de Fuenterrabía (1638)», en Antonia Paba y Gabriel Andrés (coords.), Encuentro de civilizaciones (1500-1750): informar, narrar, celebrar, Alcalá de Henares, Universidad de Alcalá, 2003, pp. 129-148.

Díaz Noci, Javier, Carmen Espejo Cala y Francisco Baena, «Redes y empresas informativas en España: conexiones de impresores y editores de prensa en el siglo XVII», Barcelona Quaderns d'Història, 25, (2018), pp. 75-85.

Ettinghausen, Henry, «Relaciones internacionales las relaciones de sucesos, un fenómeno paneuropeo», en Jorge García y Sònia Boadas (coords.), Las relaciones de sucesos en los cambios políticos y sociales de la Europa Moderna, Barcelona, Bellaterra, 2015, pp. 13-27.

Fernández Valladares, Mercedes, «Los problemas bibliográficos de las relaciones de sucesos. Algunas observaciones para un repertorio descriptivo (con un nuevo pliego poético del siglo XVI)», en Sagrario López Poza y Nieves Pena Sueiro (coords.), La fiesta: actas del II Seminario de Relaciones de Sucesos, A Coruña, SIELAE, 1999, pp. 107-120.

Infantes, Víctor, «¿Qué es una relación? (Divagaciones varias sobre una sola divagación)», en Henry Ettinghausen, Víctor Infantes, Augustin Redondo y María Cruz García de Enterría (coords.), Las relaciones de sucesos en España (1500-1750), Madrid, Universidad de Alcalá, 1996, pp. 203-216.

Infantes, Víctor, "La muestra de impresión: un testimonio inédito en la estrategia editorial del Siglo de Oro», en Anne Cayuela (ed.), Edición y literatura en España (siglos XVI y XVII), Zaragoza, Prensas Universitarias de Zaragoza, 2012, pp. 137-168.

López Poza, Sagrario, «Las noticias en relaciones de sucesos cercanas a la $y$ del Quijote», en Sagrario López Poca (ed.), Las noticias en los siglos de la imprenta manual. Homenaje a Mercedes Agulló, Henry Ettinghausen, María Cruz García de Enterría, Giuseppina Ledda, Augustin Redondo y José Simón, A Coruña, SIELAE \& Sociedad de Cultura Valle Inclán, 2006, pp. 119-140.

Martín Abad, Julián, «La tipobibliografia complutense del siglo XVI: tareas y posibilidades», en María Luisa López Vidriero y Pedro M. Cátedra (eds.), El libro antiguo español, Salamanca, Universidad de Salamanca, 1988, pp. 273-293.

Martín Molares, Mónica, «Paratextos legales en las relaciones de sucesos impresas entre 1550 y 1650», en Manuel José Pedraza Gracia (dir.), Doce siglos de mate- 
rialidad del libro: estudios sobre manuscritos e impresos entre los siglos VIII y XIX, Zaragoza, Prensas Universitarias de Zaragoza, 2017, pp. 365-383.

Moll, Jaime, «Las cursivas de Juan Mey, con algunas consideraciones previas sobre el estudio de las letrerías», en María Luisa López Vidriero y Pedro M. Cátedra (eds.), El libro antiguo español, Salamanca, Universidad de Salamanca, 1988, pp. 295-304.

Moll, Jaime, "Los surtidos de romances, coplas, historias y otros papeles», en Enrique Rodríguez Cepeda (ed.), Actas del Congreso Romancero-Cancionero, Madrid, José Porrúa Turanzas, 1990, vol. I, pp. 205-216.

Moll, Jaime, Problemas bibliográficos del libro del Siglo de Oro, Madrid, Arco Libros, 2011.

Pedraza Gracia, Manuel José, El libro español del Renacimiento. La vida del libro en las fuentes documentales contemporáneas, Madrid, Arco Libros, 2008.

Pena Sueiro, Nieves, «Estado de la cuestión sobre el estudio de las Relaciones de sucesos», Pliegos de Bibliofilia, 13-1, (2001), pp. 43-66.

Pena Sueiro, Nieves y Carlota Fernández Travieso, «La edición de relaciones de sucesos en español durante la Edad Moderna lugares de impresión e impresores», en Pedro Manuel Cátedra García (dir.), Géneros editoriales y relaciones de sucesos en la Edad Moderna, Salamanca, Universidad de Salamanca: SEMYR, 2013, pp. 125-145.

Pérez Goyena, Antonio, Ensayo de bibliografía navarra desde la creación de la imprenta en Pamplona hasta el año 1910, Pamplona, Diputación Foral de Navarra, 1947, vol. II.

Reyes Gómez, Fermín de los, El libro en España y América legislación y censura: (siglos XV-XVIII), Madrid, Arco Libros, 2000.

Rojo Vega, Anastasio, "Comercio e industria del libro en el noroeste peninsular: Siglo XVI», en Pedro Manuel Cátedra y María Luisa López-Vidriero (eds.), El libro antiguo español, Salamanca, Universidad de Salamanca, 1992, pp. 425-430.

Ruiz Astiz, Javier, «Negocio editorial y protoperiodismo en Navarra. Estudio de la relación de sucesos impresa por Martín de Labayen en 1647», Príncipe de Viana, 76-262, (2015), pp. 619-634.

Ruiz Astiz, Javier, «El editor y sus exigencias: convenios de impresión en la Pamplona del siglo XVII», en Manuel José Pedraza Gracia (dir.), Doce siglos de materialidad del libro: estudios sobre manuscritos e impresos entre los siglos VIII y XIX, Zaragoza, Presas Universitarias de Zaragoza, 2017, pp. 401-420. 
Ruiz Astiz, Javier, «Tiene poca ciencia de lo que es latín: la prueba de imprenta como testigo del proceso editorial en el Siglo de Oro", Bulletin Hispanique, 120-1, (2018), pp. 27-50.

Ruiz Astiz, Javier, "Relaciones de sucesos impresas en Pamplona en el siglo XVII: esbozo de un repertorio bibliográfico», Memoria y Civilización, 22, (2019), pp. 1-47.

Ruiz Astiz, Javier y Nieves Pena Sueiro, «Presentación. Las relaciones de sucesos: producto y género editorial en la Monarquía Hispánica», Memoria y Civilización, 22, (2019), pp. 1-10.

Ruiz Astiz, Javier, «La estrategia editorial en torno al suceso: la invasión de Labort de 1636 en las prensas hispánicas», en Luc Torres, Hélène Tropé y Javier Espejo (eds.), Metamorfosis y memoria del evento. El acontecimiento en las relaciones de sucesos europeas de los siglos XVI al XVIII, Rennes, Université Rennes 2. (En prensa). 